\title{
Medical Image of the Month: An "Intubation Box" to Protect Healthcare Professionals
}

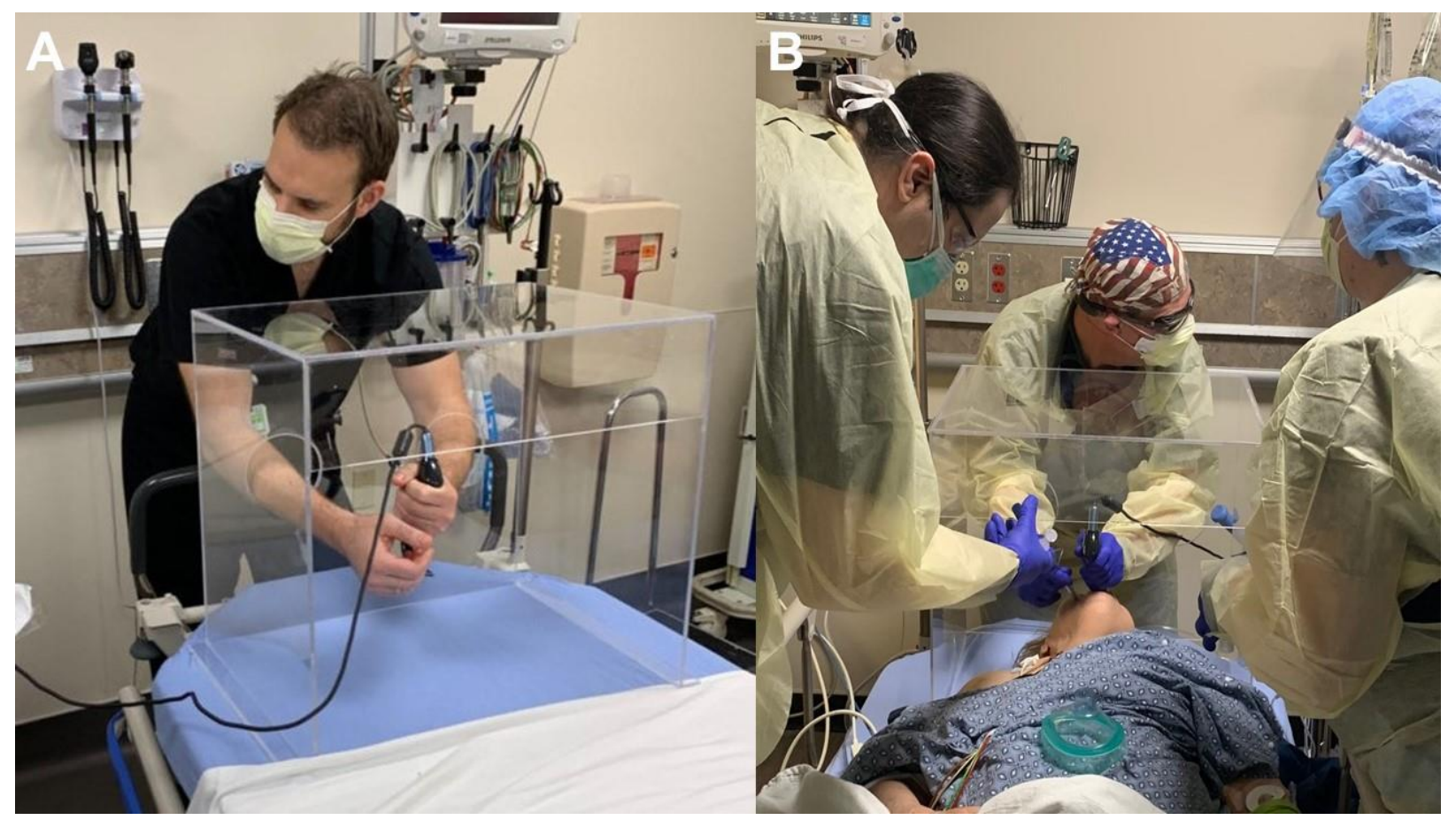

Figure 1. A: Intubation box. B: Intubation box in use.

The COVID-19 pandemic has emerged as growing global healthcare crisis. There is evidence of transmission of the Severe Acute Respiratory Syndrome Coronavirus 2 (SARC-CoV-2) from aerosolized spread to personal protective equipment worn by healthcare professionals (1). In an attempt to mitigate hazards to healthcare professionals during the COVID-19 pandemic, particularly those at greater risk to exposure during endotracheal intubation, an Intubation Box has been designed by our Emergency Department (Figure 1A) (2). This is an inexpensive apparatus adjusted to include patients of large body habitus. We illustrate use of the box during endotracheal intubation using video laryngoscopy (Figure 1B). The box protects providers from aerosolized particulate and can be cleaned between each use with anti-viral reagents such as bleach-based or alcohol-based solutions. It is assembled in under one hour using acrylic with acrylic adhesive or equivalent plastic welding adhesive. Information on how to build this box in several easy steps, or how to order boxes, are provided for hospitals around the world at http://www.intubationbox.com.

Lavi Nissim MD ${ }^{1}$ and Benjamin Reeser $\mathrm{MD}^{2}$

Departments of ${ }^{1}$ Radiology and ${ }^{2}$ Emergency Medicine

Abrazo Central Campus

Phoenix, AZ USA 


\section{References}

1. Ong SWX, Tan YK, Chia PY, Lee TH, Ng OT, Wong MSY, Marimuthu K. Air, Surface Environmental, and Personal Protective Equipment Contamination by Severe Acute Respiratory Syndrome Coronavirus 2 (SARS-CoV-2) From a Symptomatic Patient. JAMA. 2020 Mar 4. [Epub ahead of print] [CrossRef] [PubMed]

2. Cook TM. Personal protective equipment during the coronavirus disease (COVID) 2019 pandemic - a narrative review. Anaesthesia. 2020 Apr 4. [Epub ahead of print] [CrossRef] [PubMed] 